\title{
Investigação sobre a Eficiência da Fibra de Vidro e da Fibra Cerâmica como Suporte de Solda na Soldagem Unilateral
}

\author{
(Investigation over the Eficiency of Fiber Glass and Ceramic Fiber as Weld Support in One-Sided Welding)
}

Luiz Cláudio Tatagiba1, Angelus Giuseppe Pereira da Silva2, Ronaldo Paranhos2

${ }^{1}$ E\&P-SERV/US-SUB-PETROBRAS. Macaé, RJ, Brasil. luiztatagiba@petrobras.com.br.

${ }^{2} U E N F-C C T-L A M A V$, Campos dos Goytacazes, RJ, Brasil.paranhos@uenf.br.

\begin{abstract}
Resumo
O objetivo deste trabalho foi avaliar uma nova categoria de suporte de solda para a soldagem unilateral do aço carbono, usando tecidos de fibra de vidro e fibra cerâmica. Trata-se de uma proposta de inovação tecnológica, uma evolução do suporte cerâmico convencional. A soldagem unilateral com este tipo de suporte de solda foi executada em chapas de aço carbono com arame tubular (FCAW) e MIG-MAG (GMAW). A eficiência da fibra de vidro e da fibra cerâmica em suportar o metal de solda líquido foi verificada durante a soldagem do passe de raiz. Várias espessuras e combinações de tecidos de fibra de vidro e fibra cerâmica foram testadas, bem como foram identificados pontos de trabalho. As seguintes variáveis do processo foram estudadas: a abertura de raiz, a corrente e a velocidade de soldagem. Os resultados mostram que os materiais à base de fibra de vidro e fibra cerâmica são eficientes para suportar a poça de solda líquida. O modo de fixação do suporte de solda na junta soldada também mostrou ser efetivo. Foi possível estimar uma faixa de operação do processo, com abertura de raiz de 2,0 a 4,0 mm, a energia de soldagem menor que 1,8 kJ/mm, a técnica de soldagem ligeiramente puxando e com pequena oscilação da tocha, espessura do suporte de solda de tecido de fibra de vidro maior que 1,6 mm. Macrogafias da juntas soldadas mostraram que houve penetração nas laterais do chanfro, reforço de solda adequado na raiz. e não foram notados defeitos.
\end{abstract}

Palavras-chave: soldagem unilateral, suporte de solda, fibra de vidro, fibra cerâmica.

Abstract: The objective of this work was to evaluate a new chategory of weld support for the one-sided welding of carbon steel, using fiber glass and ceramic fiber tissues. This is a proposal of techonological innovation proposed, an evolution of the conventional ceramic support. The one-sided welding with this type of weld support was made in carbon steel with FCAW and GMAW. The efficiency of fiber glass and ceramic fiber was verified during the root weld bead. Several thicknesses and combinations of glass and ceramic fibers were tested. Working points were identified. The following variables were studied: root gap, welding current and travel speed. The results show that materials based on fiber glass are effective to support the liquid weld pool. The way the weld support was fixed in the welded joint also shown to be effective. It was possible to estimate a working range of the process, with root gap of 2,0 to 4,0 mm, heat input lower than 1,8 kJ/mm, pull welding technique with some oscilattion of the torch, thickness of the weld support higher than 1,6 mm. Macrographs of the welding joints show that there was penetration on the groove sides, adequate reinforcement in the root and no defects were observed.

Key words: One-sided welding, weld support, fiber glass, ceramic fiber

\section{Introdução}

O suporte de solda é usado quando o metal base não apresenta massa suficiente para fornecer um adequado anteparo para a poça de solda líquida, ou quando se precisa obter completa penetração da solda em um único passe. Devido à soldagem gerar uma poça de solda de grande volume, que permanece fluida por um relativo período de tempo, torna-se essencial que o metal fundido tenha um suporte até sua total solidificação [1].

Entre os vários métodos para suporte da poça de solda,

(Recebido em 18/10/2011; Texto final em 19/10/2011). o suporte cerâmico tem sido o mais freqüentemente usado na soldagem do aço [1]. A soldagem unilateral com suporte de solda cerâmico é considerada um processo de alta produtividade [2,3], pois elimina a necessidade de virar a peça para soldar o lado oposto suprime trabalhos extras de preparação na montagem antes da soldagem.

$\mathrm{O}$ aspecto rígido e frágil da cerâmica impede que esta se molde adequadamente de acordo com os vários formatos de chanfros da soldagem. Sua aplicação é mais favorável para chanfros retilíneos. Em soldas circunferenciais, apenas diâmetros superiores a $600 \mathrm{~mm}$ podem receber o suporte cerâmico articulado. [4].

Uma pesquisa bibliográfica [5,6] identificou características e propriedades que a fibra de vidro e fibra cerâmica apresentam que são comuns às cerâmicas, o que permitiria seu potencial 
uso como materiais para suporte da poça de solda. Entre estas, ressaltam-se:

- Temperatura de fusão elevada, em torno de $1540^{\circ} \mathrm{C}$, ligeiramente superior à do aço;

- Por ser fabricado por processo de fusão da sílica, não gera gases. Evita defeitos no cordão de solda;

- Disponivel no mercado grande variedade de produtos de fibra de vidro e fibra cerâmica, como tecidos e fios contínuos, com diferentes formatos e espessuras;

- Fios contínuos e tecidos de fibra de vidro são produtos de baixo custo, gerando suporte de solda também de baixo custo;

- É flexível e capaz de moldar-se sobre qualquer superfície.

Estas características justificam a investigação e uso da fibra de vidro e da fibra cerâmica como materiais para suporte de solda. O suporte de solda à base de tecido de fibra de vidro, uma variação do suporte cerâmico, é uma perspectiva de produto a ser desenvolvido. Apresenta as principais características da cerâmica aliada à capacidade de moldar-se sobre qualquer superfície, diferencial importante em relação aos produtos hoje existentes.

Esta parte do trabalho testa modelos de suporte de solda à base de tecidos de fibra de vidro e fibra cerâmica, identifica as variáveis do processo e técnica de soldagem, e, por fim, propõe uma faixa de operação do processo. Foi avaliado apenas o passe de raiz. É previsto outro trabalho mostrando a caracterização de uma junta soldada.

\section{Materiais e Métodos}

O tecido de fibra de vidro usado foi o tipo WR-200 da Texiglass Indústria e Comércio Têxtil, com espessura de 0,21 mm [7]. A fibra cerâmica usada foi o tipo KAOWOOL®700E, nas espessuras de 1,6 mm e 3,2 mm da Morganite Brasil [8]. Ainda, foi usada fita adesiva dupla face Y-5369 do fabricante 3M.

As juntas a serem soldadas com os suportes de solda de fibra de vidro foram feitas em chapas A-36 com dimensões 100 X 100 X 6,4 mm, com chanfro em V e ângulo do bizel de $60^{\circ}$. A abertura da raiz variou de zero a $3 \mathrm{~mm}$. Os processos de soldagem para a confecção das juntas soldadas foram o arame tubular (FCAW) e o MIG-MAG (GMAW). A soldagem foi executada na posição plana. Os dois processos foram usados com a finalidade de alcançar uma faixa de corrente de soldagem entre 130A a 300A. Os consumíveis de soldagem utilizados foram: para o FCAW, arame E71T-1 com diâmetro 1,1 mm e $\mathrm{CO}_{2}$ como gás de proteção; para o GMAW, arame ER70S-6 com 0,8 mm de diâmetro e gás de proteção $75 \% \mathrm{Ar}$ e $25 \% \mathrm{CO}_{2}$. A vazão do gás foi de $151 /$ min. A extensão do eletrodo (stickout) variou de 18 a $25 \mathrm{~mm}$ conforme a corrente de soldagem.

A verificação da eficiência da fibra de vidro e da fibra cerâmica em suportar o metal de solda líquido durante o passe de raiz foi feita em duas etapas.

Na primeira etapa, foram confeccionados dois modelos básicos de suporte de solda. Foram usadas diferentes espessuras do tecido de fibra de vidro, que foi obtida com a sobreposição em camadas do tecido de fibra de vidro.

O primeiro modelo foi confeccionado com 4, 6 e 8 camadas sobrepostas do tecido de fibra de vidro de $50 \mathrm{~mm}$ de largura. $\mathrm{O}$ segundo modelo teve o acréscimo de uma camada de papel de fibra cerâmica conjugado com o tecido de fibra de vidro.

Para a fixação do suporte nas chapas de teste foi utilizado o próprio tecido de fibra de vidro, com largura de $100 \mathrm{~mm}$, sobre o qual foram costuradas as camadas do suporte com o fio de fibra de vidro 68/4-400. A fita adesiva dupla face Y-5369 foi fixada nas extremidades do conjunto. A Figura 1 mostra o desenho esquemático das vistas de frente e superior destes modelos com as respectivas dimensões. A figura 2 mostra o suporte de solda montado. A Figura 3 mostra o suporte e a chapa antes da montagem do conjunto e montado na chapa pronto para a soldagem.

A tabela 1 mostra as características construtivas do suporte de solda e a abertura de raiz usada para os 17 experimentos realizados. Durante a soldagem pelos processos FCAW e GMAW, foram monitoradas a corrente (I), a tensão (V) e a velocidade de soldagem (v). A energia de soldagem (ES) foi calculada conforme $\mathrm{ES}(\mathrm{kJ} / \mathrm{mm})=(\mathrm{V}$ x I x 60)/(v x 1000). Estes valores serão apresentados no item resultados e discussão. Somente o passe de raiz foi executado nesta etapa. A avaliação da qualidade superficial das soldas produzidas foi por meio dos ensaios não destrutivos de inspeção visual e por líquido penetrante.

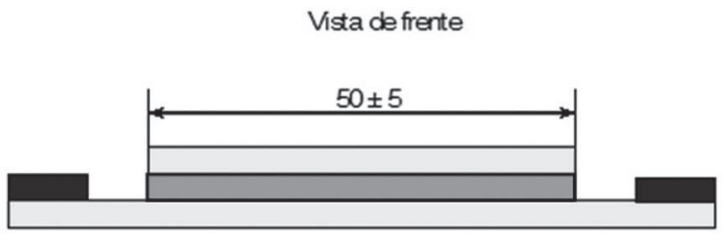

Vista superior

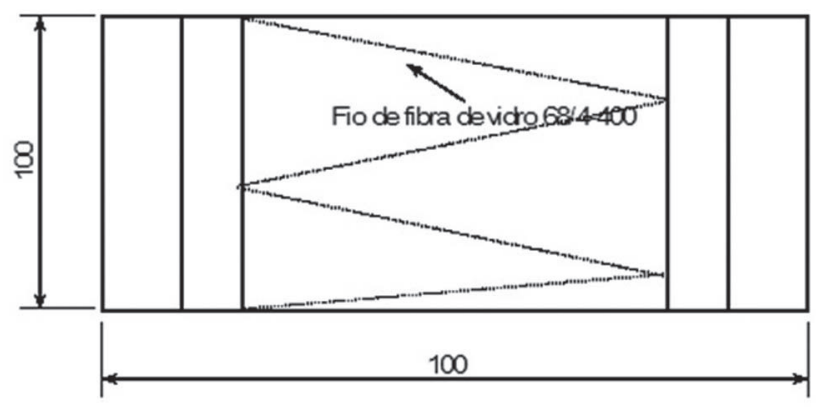

Legenda:

$\square$ Tecido WR-200 - $n$ camadas

$\square$ Papel de fibra cerâmica KAOWOOL(a)700E - 1 camada (quando aplicável)

Fita adesiva dupla face $Y-5369$

Obs.: dimensões em mm

Figura 1 - Desenho esquemático com as vistas frontal e superior com dimensões dos modelos de suportes de solda à base de fibra de vidro 


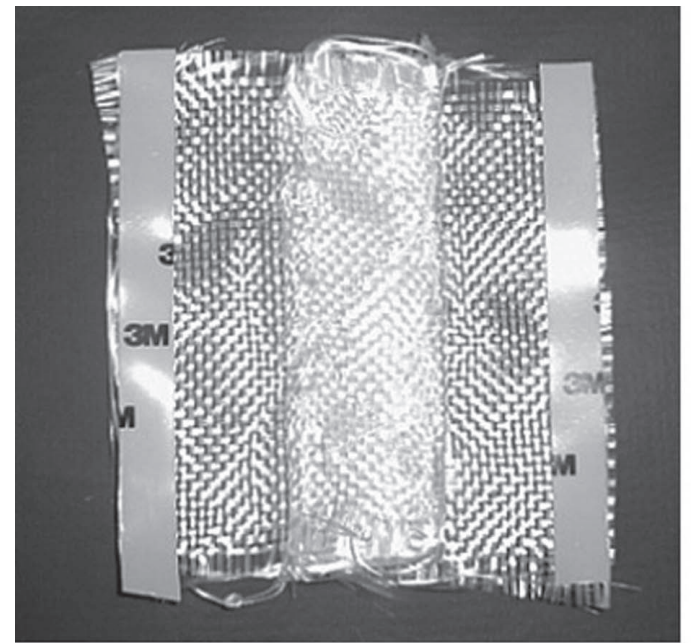

(a)

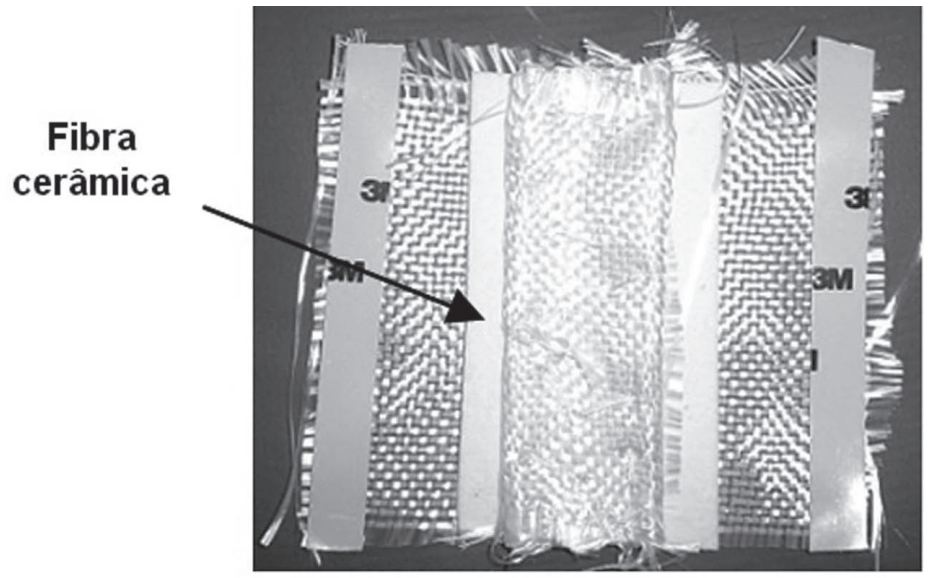

(b)

Figura 2 - (a) Suporte de solda de tecido de fibra de vidro; (b) Suporte de solda de tecido de fibra de vidro conjugado com fibra cerâmica

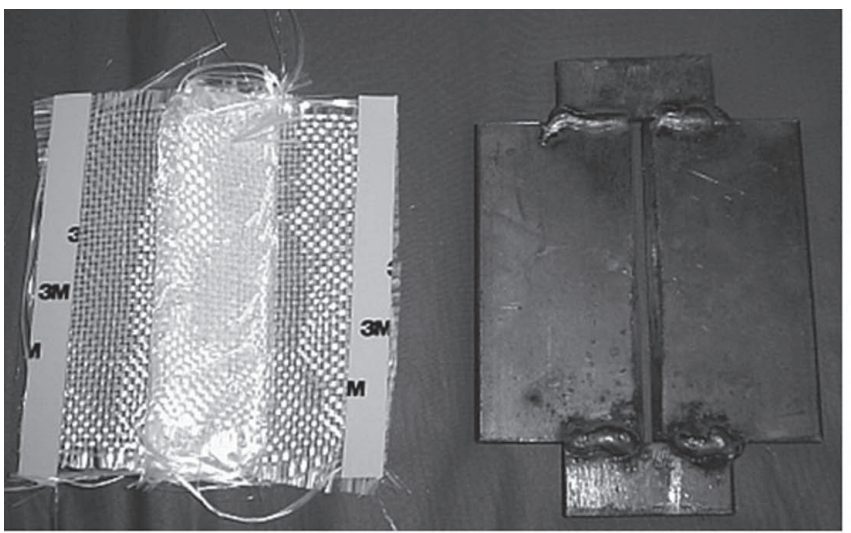

(a)

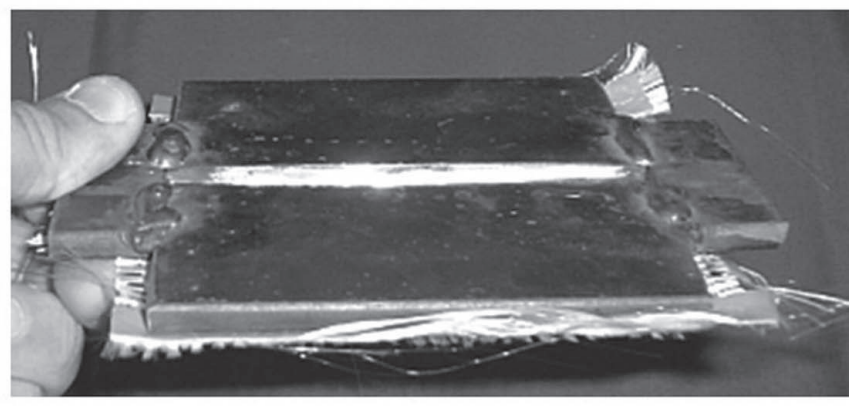

(b)

Figura 3 - (a) Suporte de solda e chapa antes da montagem do conjunto; (b) Suporte de solda montado na chapa pronto para a soldagem.

Tabela 1 - Características construtivas do suporte de solda e abertura de raiz (etapa 1)

\begin{tabular}{|c|c|c|c|}
\hline Junta & Abertura de raiz $(\mathrm{mm})$ & N. $^{\circ}$ camadas tecido fibra de vidro & \multicolumn{2}{c|}{ N. $^{\circ}$ camadas tecido fibra cerâmica } \\
\hline \multicolumn{5}{|c|}{ Processo de soldagem FCAW } \\
\hline 1 & 0 & 8 & 0 \\
\hline 2 & 3 & 8 & 0 \\
\hline 3 & 2 & 8 & 1 \\
\hline 4 & 3 & 8 & 0 \\
\hline 5 & 3 & 6 & 0 \\
\hline 6 & 0 & 6 & 1 \\
\hline 7 & 3 & 6 & 1 \\
\hline 8 & 3 & 6 & 0 \\
\hline 9 & 2 & 4 & 1 \\
\hline 10 & 0 & 4 & 1 \\
\hline 11 & 3 & 4 & 0 \\
\hline 12 & 2 & 4 & 0 \\
\hline \multicolumn{7}{|c|}{} & Processo de soldagem GMAW & 1 \\
\hline 13 & 3 & 8 & 1 \\
\hline 14 & 3 & 4 & 1 \\
\hline 15 & 3 & 8 & \\
\hline 16 & 3 & 4 & \\
\hline 17 & 3 & \multicolumn{2}{c|}{} \\
\hline
\end{tabular}


A etapa 2 consistiu na determinação do campo operacional para utilização do suporte de solda à base de tecido de fibra de vidro e fibra cerâmica. Dois novos tipos de suportes foram confeccionados, com base na experiência adquirida da etapa anterior.

O primeiro modelo de suporte foi preparado com 08 camadas de tecido de fibra de vidro de $0,21 \mathrm{~mm}$ cada $(1,68 \mathrm{~mm}$ de espessura total). $\mathrm{O}$ segundo com 4 camadas de tecido de fibra de vidro de $0,21 \mathrm{~mm}$ cada e uma camada de papel de fibra cerâmica de espessura 1,6 mm (2,08 mm de espessura total). Em ambos os modelos, as camadas sobrepostas foram unidas por costura com o fio de fibra de vidro 68/4-400. O método de fabricação dos suportes foi similar ao utilizado na etapa anterior. A Figura 4 mostra um suporte preparado para esta etapa.

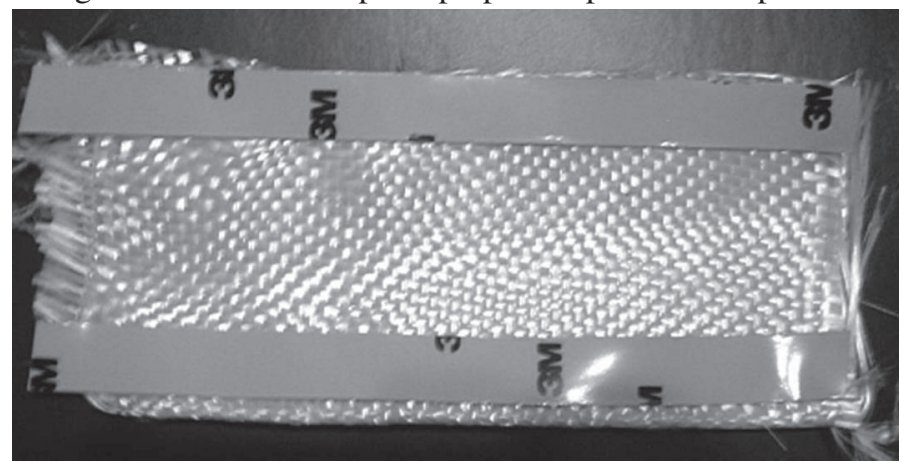

Figura 4 - Suporte utilizado na segunda fase sem a camada de tecido utilizada para fixação na chapa de teste.

Para a soldagem do passe de raiz foi utilizado o processo de soldagem GMAW em chapas de teste com as mesmas dimensões das utilizadas na etapa anterior. Nesta etapa também foi depositado apenas o passe de raiz. A tabela 2 identifica os 12 experimentos realizados nesta etapa, a abertura de raiz e as características do suporte de solda usado.

Tabela $2-\mathrm{N} .^{\circ}$ de juntas soldadas, características construtivas do suporte de solda (etapa 2)

\begin{tabular}{|c|c|}
\hline $\begin{array}{c}\text { Suporte com } 8 \text { camadas de tecido de fibra de vidro de } 0,21 \\
\text { mm cada }(1,68 \mathrm{~mm} \text { de espessura total })\end{array}$ \\
\hline Junta & Abertura de raiz $(\mathrm{mm})$ \\
\hline 18 & 0,0 \\
\hline 19 & 2,0 \\
\hline 20 & 4,0 \\
\hline 27 & 0,0 \\
\hline 29 & 2,0 \\
\hline
\end{tabular}

Suporte com 4 camadas de tecido de fibra de vidro de 0,21 mm cada e uma camada de papel de fibra cerâmica na espessura de $1,6 \mathrm{~mm}(2,08 \mathrm{~mm}$ de espessura total $)$

\begin{tabular}{|c|c|}
\hline Junta & Abertura de raiz $(\mathrm{mm})$ \\
\hline 21 & 0,0 \\
\hline 22 & 2,0 \\
\hline 23 & 4,0 \\
\hline 24 & 0,0 \\
\hline 25 & 2,0 \\
\hline 26 & 4,0 \\
\hline
\end{tabular}

O passe de raiz foi avaliado por inspeção visual e por líquido penetrante. Nas amostras consideradas aprovadas, macrografias foram preparadas para verificar o aspecto da seção transversal do passe de raiz de cada junta soldada. As amostras para macrografia foram obtidas por corte transversal ao cordão de solda, lixamento até 600 mesh e a superfície atacada com Nital 10\%. As macrografias foram usadas para medir a largura do cordão, a penetração lateral do passe de raiz e o reforço da face do cordão em contato com o suporte de solda, com o auxílio de um paquimetro.

Para determinar um possível campo operacional do processo, foi realizada uma análise qualitativa das seguintes variáveis: número de camadas de fibra de vidro do suporte de solda, abertura de raiz e energia de soldagem. A avaliação gráfica foi usada para delinear um possível campo operacional do processo. Os resultados obtidos na etapa anterior, com o processo de soldagem GMAW, também foram utilizados.

\section{Resultados e Discussão}

A etapa 1 teve como objetivo verificar a eficiência do tecido de fibra de vidro e da fibra cerâmica em suportar o metal de solda líquido durante a soldagem do passe de raiz em juntas com chanfro em V, simulando a soldagem unilateral. As juntas soldadas foram executadas com a variação dos parâmetros abertura de raiz, corrente de soldagem, velocidade de soldagem, n. ${ }^{\circ}$ de camadas de tecido de fibra de vidro e de fibra cerâmica, de forma a observar o efeito destas variáveis.

A tabela 3 mostra os parâmetros de soldagem medidos e calculados durante a soldagem, bem como destaca as juntas soldadas que suportaram o metal de solda líquido e também as que não suportaram. Das 12 juntas soldadas pelo processo FCAW somente em 6 o suporte de solda foi capaz de conter o metal de solda líquido. Para o processo GMAW, das 5 juntas soldadas 4 suportaram o metal de solda líquido.

Os resultados mostram que, em vários experimentos, o tecido de fibra de vidro conjugado ou não com fibra cerâmica resistiu à poça de fusão para suportes confeccionados com número de camadas maior ou igual a 04 , tanto para o processo GMAW como para o FCAW.

Os ensaios de inspeção visual e líquido penetrante mostraram que, nas juntas que suportaram a poça de solda, houve penetração do passe de raiz e não foram encontradas descontinuidades grosseiras na superfície. As juntas que não suportaram o metal de solda apresentaram perfurações acentuadas, ou seja, o suporte de solda não resistiu ao calor da poça de solda. A figura 5 mostra uma junta soldada pelo processo GMAW que foi considerada aprovada nos ensaios de inspeção visual e líquido penetrante. 
Tabela 3 - Características construtivas do suporte de solda e abertura de raiz (etapa 1). Parâmetros de soldagem medidos e calculados durante a execução das soldas.

\begin{tabular}{|c|c|c|c|c|c|c|c|}
\hline \multicolumn{8}{|c|}{ Processo de soldagem FCAW } \\
\hline Junta & $\begin{array}{l}\text { Abertura de } \\
\text { raiz }(\mathrm{mm})\end{array}$ & $\begin{array}{l}\text { N. }{ }^{\circ} \text { camadas de } \\
\text { fibra de vidro }\end{array}$ & $\begin{array}{l}\text { N. }{ }^{\circ} \text { camadas de } \\
\text { fibra cerâmica }\end{array}$ & Tensão (V) & Corrente (A) & $\begin{array}{l}\text { Velocidade } \\
(\mathrm{mm} / \mathrm{min})\end{array}$ & $\begin{array}{c}\text { Energia soldagem } \\
\qquad(\mathrm{kJ} / \mathrm{mm})\end{array}$ \\
\hline \multicolumn{8}{|c|}{ Processo de soldagem FCAW } \\
\hline 1 & 0,0 & 8 & 0 & 32,2 & 264 & 338 & 1,51 \\
\hline 2 & 3,0 & 8 & 0 & 31,4 & 262 & 285 & 1,73 \\
\hline 3 & 2,0 & 8 & 1 & 29,2 & 256 & 171 & 2,62 \\
\hline 4 & 3,0 & 8 & 1 & 29,2 & 240 & 195 & 2,15 \\
\hline 5 & 3,0 & 6 & 0 & 29,2 & 248 & 202 & 2,15 \\
\hline 6 & 0,0 & 6 & 0 & 29,2 & 140 & 223 & 1,10 \\
\hline 7 & 3,0 & 6 & 1 & 27,2 & 204 & 182 & 1,83 \\
\hline 8 & 3,0 & 6 & 1 & 25,6 & 244 & 286 & 1,31 \\
\hline 9 & 2,0 & 4 & 0 & 25,6 & 160 & 246 & 1,00 \\
\hline 10 & 0,0 & 4 & 0 & 32,0 & 176 & 225 & 1,50 \\
\hline 11 & 3,0 & 4 & 1 & 26,4 & 168 & 213 & 1,25 \\
\hline 12 & 2,0 & 4 & 1 & 26,4 & 184 & 200 & 1,46 \\
\hline \multicolumn{8}{|c|}{ Processo de soldagem GMAW } \\
\hline 13 & 3,0 & 8 & 0 & 21,5 & 152 & 245 & 0,80 \\
\hline 14 & 3,0 & 4 & 0 & 21,5 & 150 & 107 & 1,80 \\
\hline 15 & 3,0 & 8 & 1 & 21,5 & 150 & 228 & 0,85 \\
\hline 16 & 3,0 & 4 & 1 & 21,5 & 150 & 204 & 0,95 \\
\hline 17 & 3,0 & 4 & 1 & 21,5 & 130 & 151 & 1,11 \\
\hline \multicolumn{8}{|c|}{ Suportou o metal de solda líquido } \\
\hline
\end{tabular}

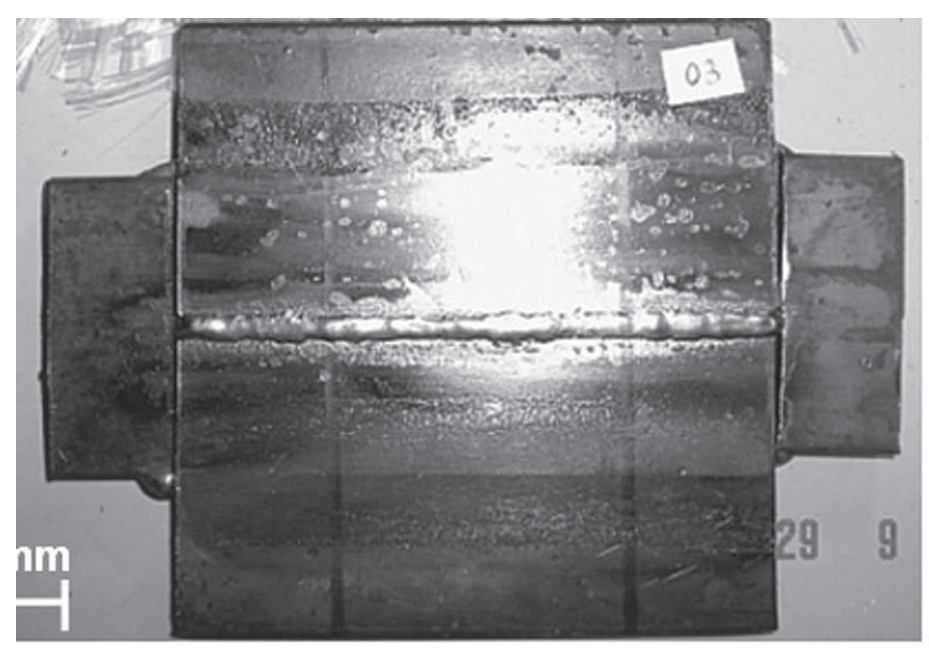

(a)

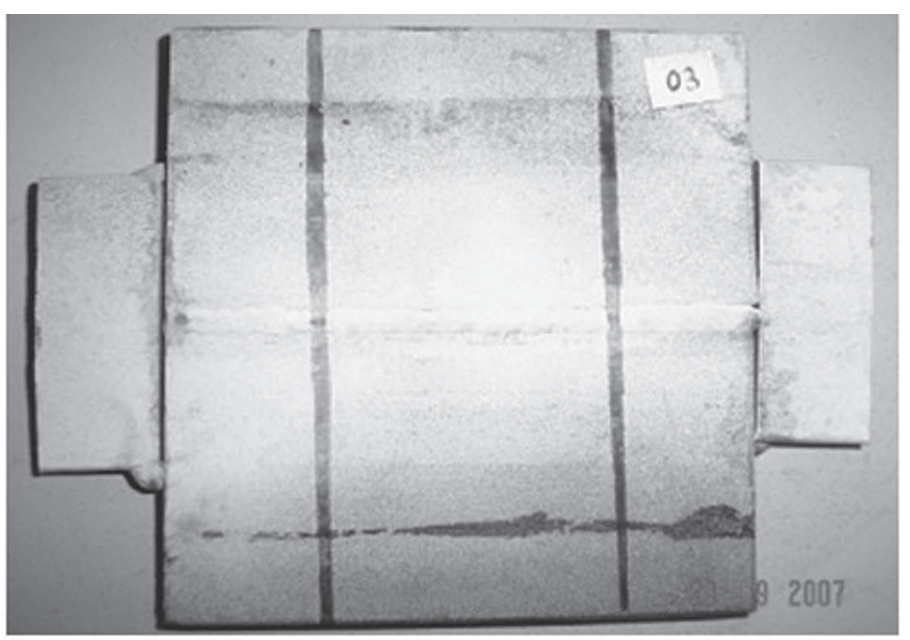

(b)

Figura 5 - Junta soldada pelo processo GMAW após (a) inspeção visual e (b) líquido penetrante. A face da solda mostrada é a que esteve em contato com o suporte de solda. Refere-se ao experimento 16. 
A técnica de soldagem do passe de raiz com o uso de suporte de solda a base de fibra de vidro e fibra cerâmica também pode ser avaliada durante os experimentos da primeira etapa. Foi concluído que é necessário que o soldador produza uma pequena oscilação da tocha de solda, evitando que o arco concentre-se todo o tempo sobre o suporte de solda. Ainda, é importante adotar a técnica de soldagem "puxando", posicionando a tocha ligeiramente para a poça de solda líquida. A técnica de soldagem retilínea e com ângulo da tocha reto deve ser evitada, pois direciona o arco elétrico diretamente sobre o suporte de solda, provocando dois inconvenientes: rasgar o suporte de solda devido ao excesso de calor do arco e produzir instabilidade do arco devido ao material do suporte ser não condutor elétrico.

As juntas soldadas pelo processo FCAW de n. ${ }^{\circ} 1,6$ e 10 , todas com abertura de raiz igual a $0,0 \mathrm{~mm}$, não houve penetração da solda. A energia de soldagem variou de 1,1 a $1,51 \mathrm{~kJ} / \mathrm{mm}$. Nestas juntas não foi possível avaliar a eficiência do tecido de fibra de vidro para suportar o metal de solda líquido.

Todas as juntas soldadas pelo processo FCAW com abertura de raiz de 2,0 $\mathrm{mm}$ (juntas 3, 9 e 12) foram aprovadas. Estes suportes foram fabricados com 8 camadas de tecido de fibra de vidro conjugado com 1 camada de fibra cerâmica (junta 3), 6 camadas de tecido de fibra de vidro conjugada com 1 camada de fibra cerâmica (junta 9) e com 4 camadas de tecido de fibra de vidro (junta 12). A energia de soldagem foi de 2,62 kJ/mm, 1,00 $\mathrm{kJ} / \mathrm{mm}$ e $1,46 \mathrm{~kJ} / \mathrm{mm}$, respectivamente.

Das 11 juntas soldadas, com abertura de raiz de $3,0 \mathrm{~mm}(6$ pelo processo FCAW e 5 pelo processo GMAW), 7 suportes de solda à base de tecido de fibra de vidro suportaram o metal de solda líquido, como descrito a seguir:

- Pelo processo FCAW as juntas soldadas 7 e 11 suportaram a poça líquida devido à relativamente baixa energia de soldagem $(1,83$ a $1,25 \mathrm{~kJ} / \mathrm{mm})$ e os suportes terem sido confeccionados com 4 a 6 camadas de tecido de fibra de vidro conjugado com 1 camada de fibra cerâmica. A junta 8 também foi aprovada apesar de o suporte ter sido confeccionado com 6 camadas de tecido de fibra de vidro, porém atribuído à baixa energia de soldagem, de $1,31 \mathrm{~kJ} / \mathrm{mm}$. As juntas 2 e 5 foram reprovadas devido à energia de soldagem elevada, $1,73 \mathrm{~kJ} / \mathrm{mm}$ e $2,15 \mathrm{~kJ} /$ $\mathrm{mm}$, e porque foi confeccionado somente com tecido fibra de vidro e conseqüentemente uma espessura total insuficiente. A junta 4 foi reprovada devido à energia de soldagem elevada $(2,15 \mathrm{~kJ} / \mathrm{mm})$ apesar de o suporte ter sido confeccionado com 8 camadas de tecido de fibra de vidro conjugado com 1 camada de fibra cerâmica.

- Pelo processo GMAW as juntas 13, 15, 16 e 17 foram aprovadas. Isto foi atribuído ao fato que os suportes de solda foram confeccionados com 8 camadas de tecido de fibra de vidro (junta 13), 8 camadas de tecido de fibra de vidro conjugado com 1 camada de fibra cerâmica (junta 15) e 4 camadas de tecido de fibra de vidro conjugado com 1 camada de fibra cerâmica (juntas 16 e 17). Ainda, a energia de soldagem foi relativamente baixa para estes experimentos, entre 0,80 a $1,11 \mathrm{~kJ} / \mathrm{mm}$. A junta 14 foi reprovada, pois foi feita com apenas 4 camadas de tecido de fibra de vidro e a energia de soldagem foi relativamente alta, de $1,80 \mathrm{~kJ} / \mathrm{mm}$, tendo havido a perfuração do suporte de solda que não resistiu ao calor da soldagem.
Com base nos resultados qualitativos apresentados acima, pode ser concluido que:

a) quanto maior a energia de soldagem e a abertura de raiz, maior deve ser o número de camadas de tecido de fibra de vidro ou fibra cerâmica necessárias. Conseqüentemente, maior a espessura final necessária para suportar a poça de solda líquida.

b) a energia de soldagem excessiva foi fator decisivo para a reprovação das juntas.

c) todos os experimentos com abertura de raiz igual a zero (1, 6 e 10 para o FCAW) não foram aprovados, devido à falta de penetração na raiz, evidenciando a necessidade de uma abertura de raiz mínima para a eficiência do processo.

Outro fato observado nesta etapa foi a efetividade do modo de fixação do suporte de solda à base de tecido de fibra vidro diretamente na junta soldada antes da soldagem. Este tipo de fixação se trata de uma inovação, pois os suportes de solda cerâmicos normalmente são fixados na junta por uma fita adesiva de alumínio [9].

Os resultados da etapa 1 indicam o potencial do tecido da fibra de vidro e fibra cerâmica em suportar a poça de fusão. Não foi observada a formação de gases durante a soldagem e foi verificado um acabamento adequado do cordão de solda, isento de descontinuidades. Estas características são similares aos resultados da soldagem unilateral com o suporte cerâmico convencional observado por Almeida et. al. [10].

A segunda etapa teve por objetivo complementar os resultados obtidos na etapa 1 , de forma a delinear um possível campo operacional para a utilização do suporte de solda à base de tecido de fibra de vidro e fibra cerâmica. O processo de soldagem MIG-MAG foi escolhido para ser utilizado nesta fase da pesquisa, devido à necessidade de limitar a energia de soldagem, como observado na etapa anterior.

A tabela 4 mostra as juntas soldadas que suportaram o metal de solda líquido e foram consideradas aprovadas, bem como as que apresentaram problemas e não foram consideradas aprovadas. Ainda, indica os parâmetros de soldagem medidos e calculados durante a soldagem. Das 6 juntas soldadas com o suporte de 08 camadas de tecido de fibra de vidro de $0,20 \mathrm{~mm}$ cada (1,6 mm de espessura total) somente 03 suportaram o metal de solda líquido (juntas 19, 20 e 28), porém a junta 19 não foi aprovada nos ensaios subseqüentes. Para as 6 juntas soldadas com o suporte de 4 camadas de tecido de fibra de vidro de 0,2 $\mathrm{mm}$ cada e uma camada de papel de fibra cerâmica, 3 juntas suportaram o metal de solda líquido (juntas 22, 25 e 26). Todas as juntas com abertura de raiz igual a zero $(18,21,24$ e 27) apresentaram falta de fusão na raiz.

A figura 6 mostra a junta soldada n. $^{\circ} 28$, que foi considerada aprovada nos ensaios de inspeção visual e de líquido penetrante. As macrografias das juntas cujo desempenho em soldagem foi considerado satisfatório na segunda etapa (juntas 20, 22, 25, 26 e 28) são apresentadas na figura 7 . Todas apresentaram um formato do cordão de solda satisfatório, com uma adequada geometria do passe de raiz. Observa-se que houve fusão na lateral do chanfro, e que o contato da fibra de vidro com o metal de solda líquido produziu um acabamento adequado na face oposta à deposição do cordão de solda. 
Tabela 4 -Juntas soldadas aprovadas, as reprovadas e parâmetros de soldagem medidos e calculados durante a execução das soldas.

\begin{tabular}{|c|c|c|c|c|c|c|}
\hline Junta & Abertura de raiz (mm) & Tensão $(\mathrm{V})$ & Corrente $(\mathrm{A})$ & Velocidade (mm / min) & Energia de soldagem (kJ/mm) \\
\hline \multicolumn{7}{|c|}{ Suporte com 08 camadas de tecido de fibra de vidro de 0,21 mm cada (1,68 mm de espessura total) } \\
\hline 18 & 0,0 & 21 & 120 & 229 & 0,66 \\
\hline 19 & 2,0 & 21 & 114 & 782 & 0,79 \\
\hline 20 & 4,0 & 20 & 22 & 187 & 321 & 0,77 \\
\hline 27 & 0,0 & 22 & 207 & 300 & 0,91 \\
\hline 28 & 2,0 & 22 & 191 & 229 & 1,10 \\
\hline 29 & 4,0 & 22 & & \\
\hline
\end{tabular}

Suporte com 4 camadas de tecido de fibra de vidro de 0,21 mm cada e uma camada de papel de fibra cerâmica na espessura de 1,6 $\mathrm{mm}(2,08 \mathrm{~mm}$ de espessura total)

\begin{tabular}{|l|l|l|l|l|l|}
\hline 21 & 0,0 & 22 & 185 & 444 & 0,55 \\
\hline 22 & 2,0 & 22 & 188 & 314 & 0,79 \\
\hline 23 & 4,0 & 22 & 185 & 122 & 2,00 \\
\hline 24 & 0,0 & 22 & 177 & 584 & 0,40 \\
\hline 25 & 2,0 & 21 & 129 & 166 & 0,98 \\
\hline 26 & 4,0 & 21 & 134 & 98 & 1,72 \\
\hline \multicolumn{7}{|r|}{ Suportou o metal de solda líquido } \\
\hline
\end{tabular}

Tabela 5 - Avaliação dimensional (largura, penetração lateral e reforço) nas macrografias.

\begin{tabular}{|c|c|c|c|c|}
\hline Junta & Abertura de raiz $(\mathrm{mm})$ & Largura do Cordão $(\mathrm{mm})$ & Penetração $(\mathrm{mm})$ & Reforço $(\mathrm{mm})$ \\
\hline 20 & 4,0 & 8,0 & 2,0 & 2,6 \\
\hline 22 & 2,0 & 6,5 & 2,2 & 0,8 \\
\hline 25 & 2,0 & 5,0 & 1,5 & 0,7 \\
\hline 26 & 4,0 & 5,5 & 0,8 & 2,0 \\
\hline 28 & 2,0 & 5,0 & 1,5 & 1,0 \\
\hline
\end{tabular}

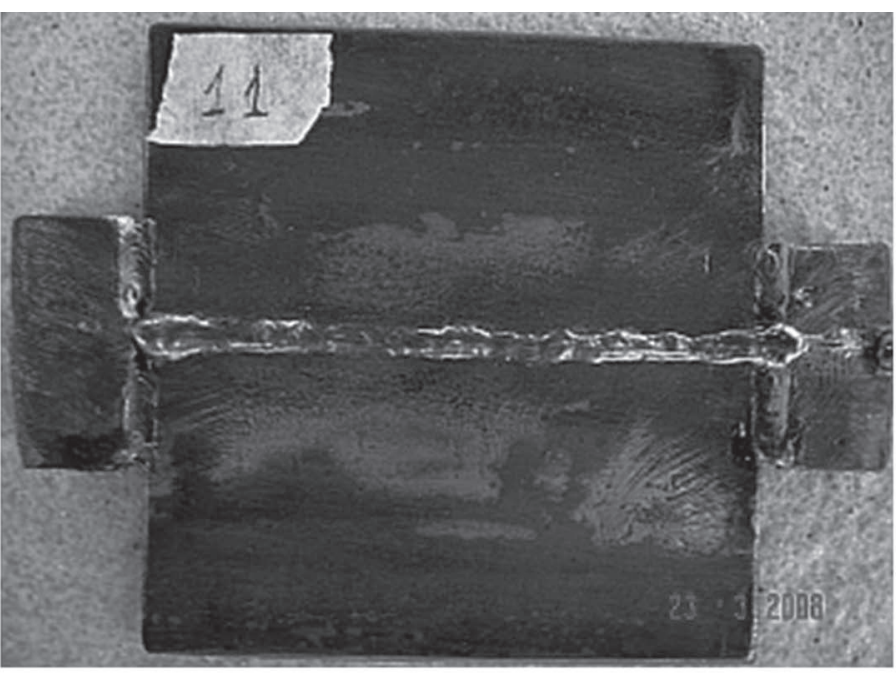

(a)

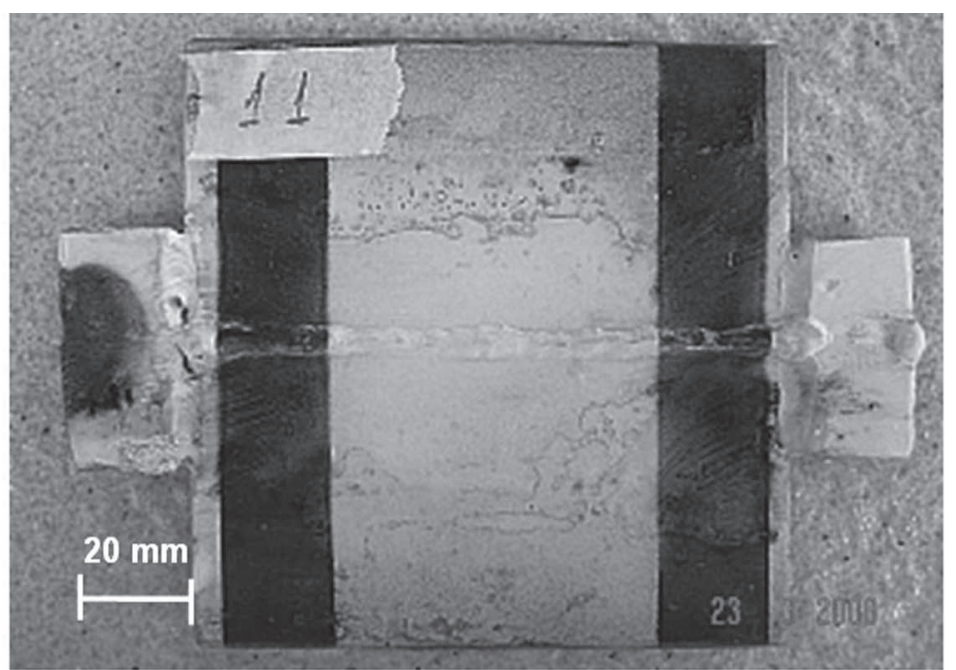

(b)

Figura 6 - Junta soldada n. ${ }^{\text {o } 28}$, após ensaios de (a) inspeção visual e (b) liquido penetrante. 


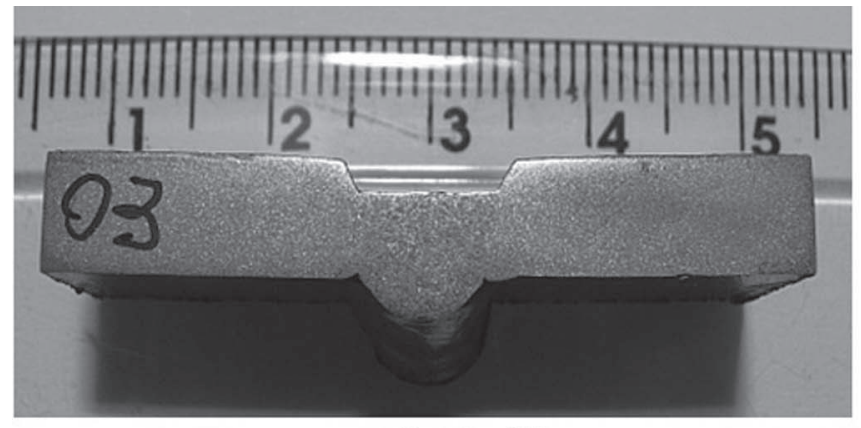

Junta 20

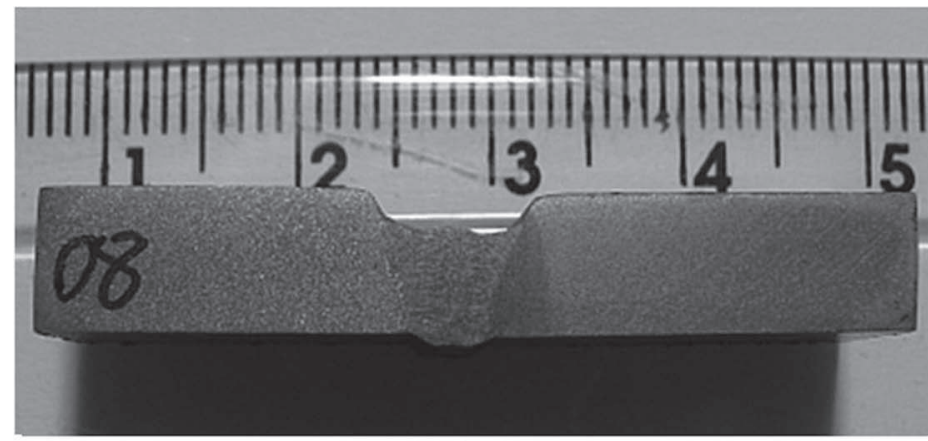

Junta 25

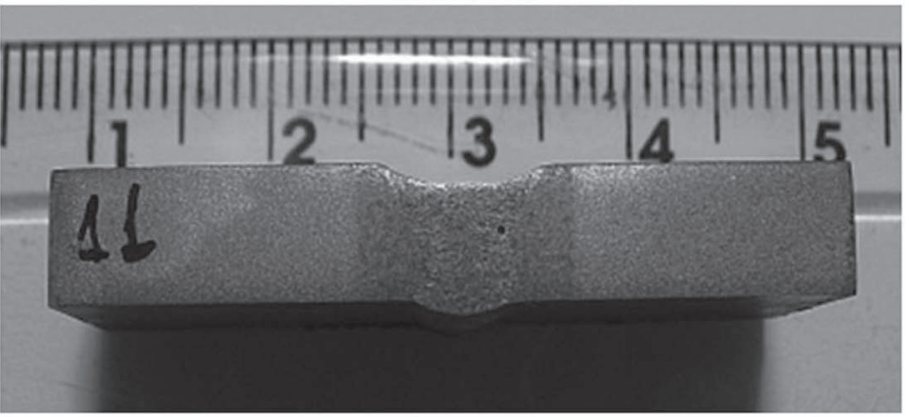

Junta 28

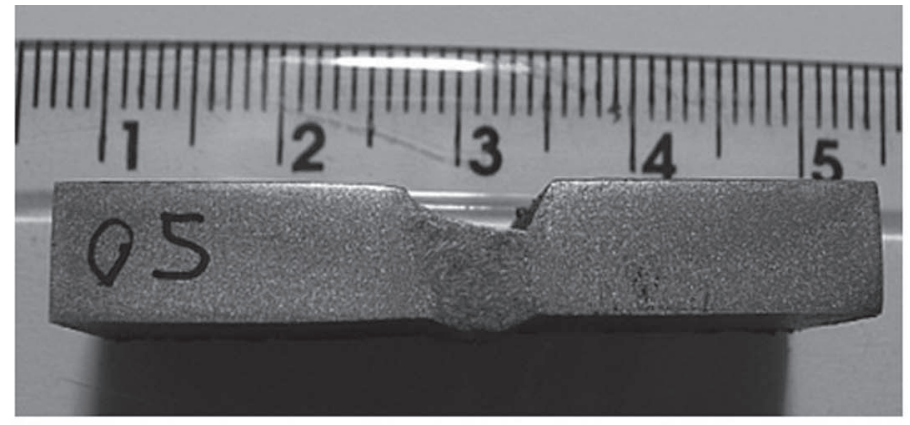

Junta 22

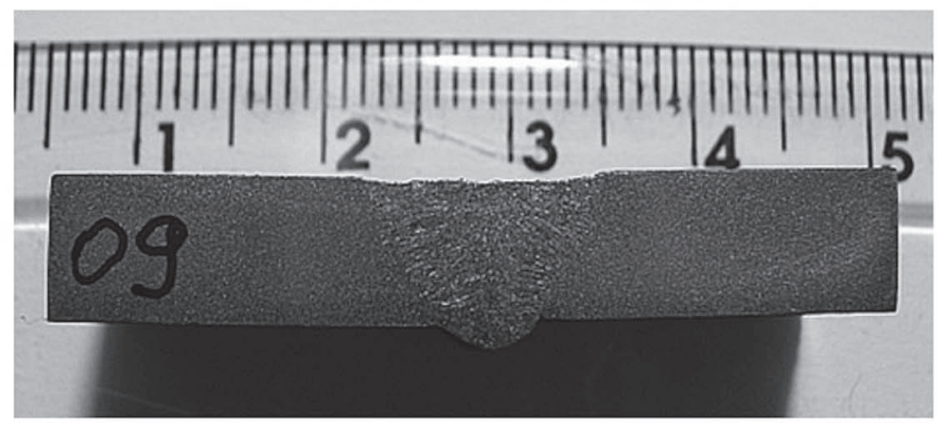

Junta 26

Figura 7 - Macrografias das juntas consideradas aprovadas na segunda etapa (20, 22, 25, 26 e 28).

A Tabela 5 mostra os resultados da avaliação dimensional (largura, penetração lateral e reforço) medida nas macrografias da figura 7. Pode ser observado que a largura do passe de raiz variou de 5,0 a 8,0 mm, a penetração lateral na base do chanfro variou de 0,8 a 2,2 $\mathrm{mm}$, e o reforço do cordão na face em contato com o suporte de solda variou de 0,7 a 2,6 mm.

Os experimentos realizados para o processo GMAW (13 a 17 na etapa 1 e 18 a 28 na etapa 2), foram considerados para estimar um possível campo operacional do processo. A figura 8 mostra a energia de soldagem $(\mathrm{kJ} / \mathrm{mm})$ versus a abertura da raiz (mm) para estes 17 experimentos, tendo sido possível delinear qualitativamente um campo operacional do processo. A figura 8 mostra que:

- Para abertura de raiz igual a zero (4 juntas) não houve penetração da solda, portanto, não é adequada para esta técnica de soldagem, devido à restrição construtiva do chanfro.

- Para abertura de raiz de 2,0 mm os dois modelos de suporte suportaram o metal de solda líquido. A energia de soldagem foi relativamente baixa, na faixa de 0,80 a $1,00 \mathrm{~kJ} / \mathrm{mm}$ em todas as 4 juntas soldadas.
- Para abertura de 3,0 mm também os dois modelos de suporte em 4 juntas soldadas suportaram o metal de solda líquido, com a energia de soldagem na faixa de 0,80 a $1,10 \mathrm{~kJ} /$ mm. Em uma junta o suporte de solda não suportou a poça de solda, que se rompeu durante a soldagem. Isto foi atribuído à excessiva energia de soldagem de $1,80 \mathrm{~kJ} / \mathrm{mm}$.

- Para abertura de 4,0 mm, das 4 juntas soldadas, duas foram reprovadas, uma com energia de soldagem relativamente baixa e outra relativamente alta, 1,1 e 2,0 $\mathrm{kJ} / \mathrm{mm}$ respectivamente, indicando que a abertura de raiz de $4,0 \mathrm{~mm}$ é o limite máximo que pode ser usado, mesmo assim com algum critério.

- Os experimentos que obtiveram sucesso com o suporte com 4 camadas de tecido de fibra de vidro estavam conjugados com uma camada de fibra cerâmica;

- A técnica de soldagem com oscilação da tocha e ligeiramente puxando foi considerada adequada um bom resultado na soldagem. Esta técnica direciona a pressão exercida pelo arco durante a transferência do metal de solda para a poça de solda e para as laterais do chanfro no metal de base, pois a fibra de vidro não é condutora elétrica. 


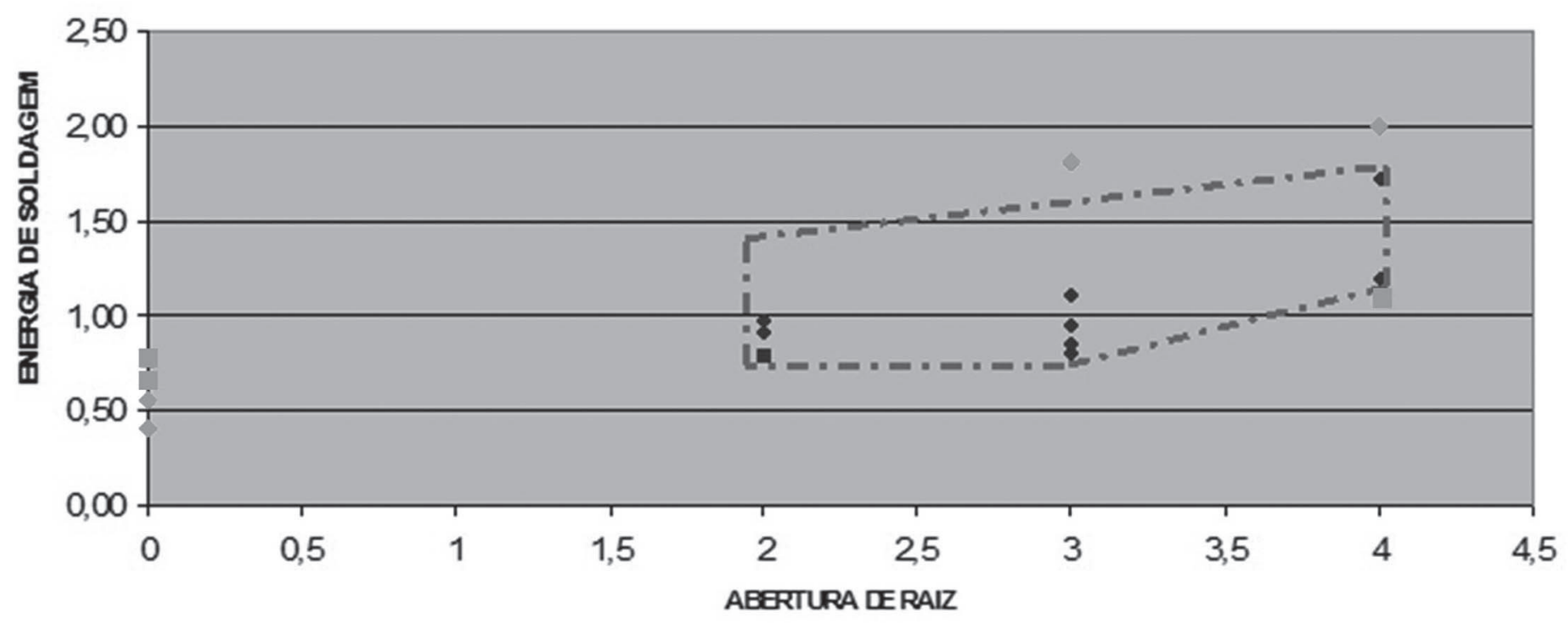

I.egenda:

4 camadas de tecido de fibra de vidro aprovado

8 camadas de tecido de fibra de vidro aprovado

4 camadas de tecido de fibra de vidro reprovado

8 camadas de tecido de fibra de vidro reprovado

Figura 8 - Gráfico delineando um possível campo operacional determinado pela análise qualitativa

Tabela 6 - Faixa operacional de soldagem da raiz para avaliação da junta soldada com o suporte de solda à base de fibra de vidro

\begin{tabular}{|l|r|}
\hline Abertura de raiz $(\mathrm{mm})$ & 2,0 a 4,0 \\
\hline Energia de soldagem $(\mathrm{kJ} / \mathrm{mm})$ & Menor que 1,80 \\
\hline Técnica de soldagem & Pequena oscilação e puxando. \\
\hline Material do suporte de solda & Tecido de fibra de vidro \\
\hline N. ${ }^{\circ}$ de camadas / espessura $(\mathrm{mm})$ do suporte de solda & Maior que 8 / maior que 1,7 $\mathrm{mm}$ \\
\hline
\end{tabular}

Com o comportamento observado acima, foi possível estimar uma faixa de operação para soldagem, válida para a posição plana, chanfro com ângulo de $60^{\circ}$, processo GMAW, arame ER70S-6 de 0,8 mm de diâmetro, gás de proteção $\mathrm{Ar}-\mathrm{CO}_{2}$ $25 \%$, vazão de 13 a 15 1/min, apresentado na tabela 5 .

Esta faixa operacional mostra semelhança com parâmetros utilizados para a soldagem com o suporte cerâmico convencional $[10,11]$. Observa-se ainda que os resultados dos ensaios nãodestrutivos, para os experimentos realizados na faixa operacional, não detectaram descontinuidades como inclusões, trincas, poros e mordeduras ao longo do cordão de solda. As macrografias apresentaram penetração nas laterais do chanfro, reforço de solda adequado na raiz e não foram notadas descontinuidades. A dureza do passe de raiz é adequada, indicando que a deposição de passes sucessivos deve ser benéfica às propriedades da junta soldada.

\section{Conclusões}

O estudo realizado neste trabalho, sobre a investigação da fibra de vidro e fibra cerâmica como materiais para suporte de solda, pode-se concluir que:

Materiais à base de fibra de vidro e cerâmica mostraram ser eficientes para suportar a poça de fusão. Não houve formação de gases durante a soldagem e proporcionou um cordão de solda com acabamento adequado, isento de descontinuidades.

A espessura do suporte de solda deve ser acima de 1,6 mm ou 8 camadas de tecido de fibra de vidro com $0,2 \mathrm{~mm}$ espessura.

O modo de fixação do suporte de solda na junta soldada com tecido de fibra de vidro provou ser efetivo como alternativa a fita adesiva de alumínio utilizado em suporte cerâmico.

Foi possível estimar uma faixa de operação para soldagem com os testes realizados, que demonstrou a eficiência do suporte de tecido à base de fibra de vidro: abertura de raiz de 2,0 a 4,0 $\mathrm{mm}$, a energia de soldagem menor que $1,8 \mathrm{~kJ} / \mathrm{mm}$, a técnica de soldagem com pequena oscilação e ligeiramente puxando.

\section{Agradecimentos}

Os autores agradecem ao CNPq por auxílios concedidos. 


\section{Referências Bibliográficas}

[1] PARANHOS, R. P. R., SOUZA, A. C. "Soldagem a Arco Submerso". Coleção Soldagem 2000. Rio de Janeiro. FIRJAN 1 SENAI, 87 p.1999.

[2] MUIR, J. Single side panel welding with ceramic tile backing, Metal Construction, p.651-653, Oct. 1985.

[3] JUNIOR, R. C. Soldagem com Backings Cerâmicos. In: Revista Solução ESAB, n. ${ }^{\circ}$ 11, p 55-62. 2009.

[4] XIANGSHAN WELDING BACKING FACTORY. Catálogo de produtos. Welding Backing Factory; <http://www. chinabacking.com/en/products.php> em 23/04/2007.

[5] CALLISTER JR., W. D. Ciência e Engenharia de Materiais: Uma Introdução. LTC Editora. 589 p. 2002.

[6] CHAWLA, K. K. Ceramic Matrix Composites. London. Chapman \& Hall. 415 p. 1993.

[7] TEXIGLASS. (2004). Fixa técnica de tecidos. São Paulo. Maxepoxi Industrial e Comercial Ltda.; em http://www. maxepoxi.com.br/tecnica tecidos.asp em 03/06/2007 página mantida pela TEXIGLASS

[8] THERMAL CERAMICS. Catálogo de PAPEL KAOWOOL@700E. Morganite Brasil Ltda. Rio de Janeiro, 2 p. 2000.

[9] CANTRELL, R.E. Ceramic weld backing evaluation, Welding Journal, vol. 61 pp.27-34. 1982.

[10] ALMEIDA,L.L.P., TATAGIBA,L.C.S., ROSENTHAL,R., PARANHOS,R.P.R. Soldagem Unilateral com Suporte Cerâmico de Cordierita. Soldagem e Inspeção, v.15, p.061 - 070. 2010.

[11] ANDRADE, S. T. Mapeamento do Processo Mecanizado de Soldagem Unilateral FCAW com Backing Cerâmico Aplicável no Passe de Raiz em Aço Carbono. Dissertação de Mestrado em Engenharia Mecânica, Universidade Federal de Minas Gerais UFMG, 103p. 2007. 